\title{
Requirement of phospholipase $\mathrm{C} \gamma$, the tyrosine phosphatase Syp and the adaptor proteins Shc and Nck for PDGF-induced DNA synthesis: evidence for the existence of Ras-dependent and Ras-independent pathways
}

\author{
Serge Roche ${ }^{1,2,3}$, Jane McGlade 4,5 , \\ Margaret Jones ${ }^{1}$, Gerald D.Gish ${ }^{4}$, \\ Tony Pawson ${ }^{4,6}$ and Sara A.Courtneidge ${ }^{1,7}$
}

\author{
'Differentiation Programme, European Molecular Biology Laboratory, \\ Postfach 10.2209, Meyerhofstrasse 1, 69012 Heidelberg, Germany, \\ ${ }^{4}$ Programme in Molecular Biology and Cancer, Samuel Lunenfeld \\ Research Institute, Mount Sinai Hospital and ${ }^{6}$ Department of \\ Molecular and Medical Genetics, University of Toronto, Toronto, \\ Ontario, M5G 1X5, Canada \\ ${ }^{2}$ Present address: CJF9207 INSERM faculté de Pharmacie, \\ Ave Ch. Flahaut, 34060 Montpellier, France \\ ${ }^{5}$ Present address: Amgen Institute, Ontario Cancer Institute, \\ Department of Medical Biophysics, University of Toronto, Toronto, \\ Ontario M5G 2C1, Canada \\ ${ }^{7}$ Present address: SUGEN Inc., 515 Galveston Drive, Redwood City, \\ CA 94063, USA \\ ${ }^{3}$ Corresponding author
}

We have investigated the roles of the phosphotyrosine phosphatase Syp (also called SH-PTP2), phospholipase C (PLC) $\gamma 1$, rasGTPase Activating Protein (rasGAP) and the adapter molecules Nck and Shc in the mitogenic response induced by PDGF in fibroblasts. Two separate approaches were used to inhibit the biological activity of these signalling proteins in vivo. Either glutathione $S$-transferase (GST) fusion proteins containing the SH2 domains of these proteins, or antibodies specific for these polypeptides, were microinjected into cells. GSTSH2 fusion proteins are expected to act as dominant inhibitors by competing for physiological SH2-mediated interactions, while microinjected antibodies can directly block protein functions. Inhibition of PLC $\gamma$, Syp, Shc and Nck signals blocked PDGF-stimulated cells in $G_{1}$ showing a requirement for these proteins for S-phase entry. Inhibition of rasGAP, in contrast, had no effect on S-phase entry. We next examined which of these signals were required for PDGF-induced cFos expression, a Ras-dependent event important for signalling. By using the same approaches with cells expressing $\beta$-galactosidase under the control of a $c$-fos promoter, we showed that PLC $\gamma$, Syp and She were necessary for ligand-induced cFos expression whereas Nck and phosphatidylinositol 3-kinase $\alpha$ were not. From these results we concluded that PDGF generates Ras-dependent and Ras-independent pathways important for DNA synthesis.

Keywords: DNA synthesis/PDGF receptor/Ras/ signalling/tyrosine kinase

\section{Introduction}

Many polypeptide growth factors signal via receptors having intrinsic protein tyrosine kinase activity. One of the best examples studied is the receptor for plateletderived growth factor (PDGF). This growth factor is a mitogen for several cell types including glial cells, smooth muscle cells and fibroblasts. Ligand binding induces receptor dimerization and consequent trans-phosphorylation of the receptor at several sites. These phosphorylation sites serve as docking points for the association of SH2containing proteins. For instance, signal molecules that associate with the PDGF receptor include: (i) intracellular enzymes, i.e. the cytoplasmic tyrosine kinases of the Src family (Src, Fyn and Yes), phosphatidylinositol 3-kinase (PI 3-K), phospholipase C $\gamma 1$, (PL C $\gamma 1$ ), ras GTPase Activating Protein (rasGAP) and the tyrosine phosphatase Syp (also called PTP1D or SH-PTP2); and (ii) adaptors that do not possess any intrinsic catalytic activity, i.e. the sem-5 homologue GRB-2, Shc and Nck (van der Geer and Hunter, 1994). Association of these signalling molecules with the receptor involves their $\mathrm{SH} 2$ domains. These domains are conserved non-catalytic modules of $\sim 100$ amino acids which bind tyrosine-phosphorylated sites, in which the C-terminal amino acids to the phosphotyrosine define the specificity of recognition (van der Geer and Hunter, 1994; for review, see Pawson, 1995).

Other growth factors such as lysophosphatidic acid (LPA) and bombesin bind to receptors that lack tyrosine kinase activity, but signal through the interactions with heterotrimeric $G$ proteins. Nevertheless, activation of these receptors leads to increased cytoplasmic tyrosine kinase activities that may be important for signalling. Tyrosine kinases that are stimulated by such G protein-coupled receptors have been recently identified: these include Fak (Zachary et al., 1992; Kumagai et al., 1993; Hordijk et al., 1994) and PYK2 (Lev et al., 1995), a newly characterized tyrosine kinase of the Fak family. The role of these kinases in the mitogenic response induced by these factors is currently unknown.

One of the events occurring during progression of $G_{1}$ is the early expression of genes important for cell growth. Some are genes encoding for transcription factors such as $\mathrm{cMyc}$ and $\mathrm{cFos}$. These nuclear proteins are not detectable in quiescent cells but are rapidly synthesized after the first 30 min of growth factor stimulation. Several groups have shown that both cMyc and cFos are necessary for S-phase entry induced by various mitogens (Holt et al., 1986; Studzinski et al., 1986; Nishikura and Murray, 1987; Wickstrom et al., 1988; Biro et al., 1993). The mechanism that controls mitogen-induced cFos expression is now well documented and is dependent on Ras activity (Treisman, 1994); in contrast, the molecular events leading to cMyc expression are poorly understood. Recently, we reported evidence for the existence of two separate pathways that control cFos and cMyc transcription factor expression in fibroblasts, both necessary for S-phase entry (Barone and Courtneidge, 1995). 
SHC

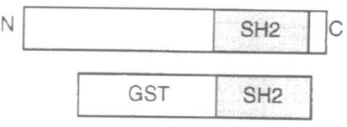

Nck

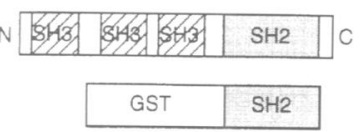

Syp

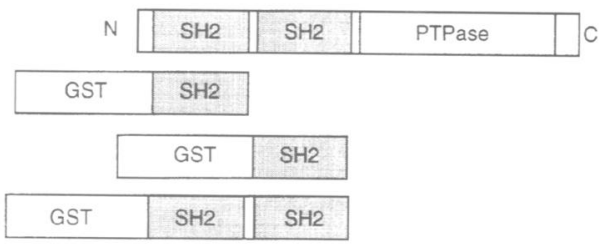

PLC $r$

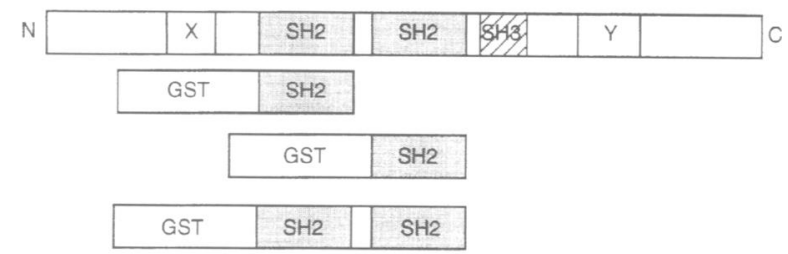

rasGAP

\begin{tabular}{|c|c|c|c|c|}
\hline$N$ & $\mathrm{SH} 2$ & 540 & $\mathrm{SH} 2$ & GTPase \\
\hline GST & SH2 & & & \\
\hline & \multicolumn{2}{|c|}{ GST } & $\mathrm{SH} 2$ & \\
\hline GST & SH2 & 803 & SH2 & \\
\hline
\end{tabular}

Fig. 1. GST fusion proteins used in this study. SH2 domains are shown in grey and SH3 domains in hatched bars. The catalytic domain of the signal molecules are shown: PTPase represents the protein tyrosine phosphatase domain. $\mathrm{X}$ and $\mathrm{Y}$ the phospholipase domains and GTPase the GTPase domain. The GST part of the chimera is also shown.

One of the main questions raised concerning growth factor signalling is which of the molecules associated with their receptor mediate the mitogenic response. To address this, several approaches have been used. For example, mutant receptors which do not associate with particular proteins have been made and the signalling capacity of the mutants analysed. However, discrepancies could be observed depending on the cell type used and the level of the receptor expressed. For example, PDGF receptor mutants that do not bind to $\operatorname{PLC} \gamma$ were able to signal when expressed in the endothelial cell line PAE (Rönnstrand et al., 1992) whereas the response was inhibited when expressed in canine kidney epithelial TRMP cells (Valius et al., 1993). Furthermore, the mutagenesis approach is not appropriate when: (i) the mutation affects the catalytic activity of the receptor [in the case of the Src family kinase binding site in the PDGF receptor (Mori et al., 1993)]; (ii) when more than one signalling molecule shares a binding site [as in the case of PI 3-K and Nck with the PDGF receptor (Nishimura, 1993)]; or (iii) when the signalling molecule binds to several sites in vivo [in the case of Shc with the PDGF receptor (Yokote

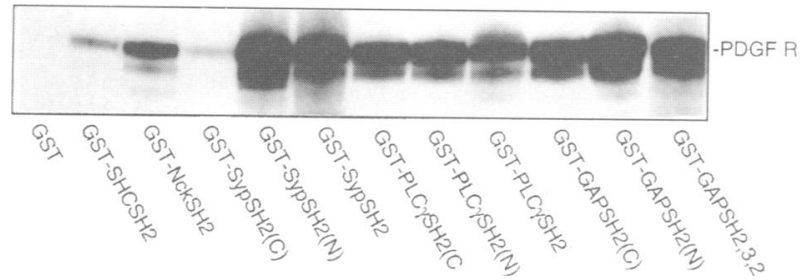

Fig. 2. In vitro association of GST fusion $\mathrm{SH} 2$ domains with the activated PDGF receptor. GST fusion $\mathrm{SH} 2$ domain proteins were bound to glutathione-Sepharose beads and incubated with Sf9 cell lysates expressing the human PDGF receptor. After extensive washing. the presence of the PDGF receptor was revealed by performing an in vitro kinase assay, followed by SDS-polyacrylamide gel separation and autoradiography. The fusion protein used and the radiolabelled PDGF receptor are indicated.

et al., 1994)]. We recently described two approaches that circumvent most of these objections, both of which rely on microinjection transiently to introduce proteins into cells (Twamley-Stein et al., 1993; Roche et al., 1995). In the first approach an excess of a dominant negative form of the protein is introduced into cells, which potentially inhibits the association of the endogenous signalling molecule with the receptor or with its effectors. In the second, an antibody specific to the protein is microinjected and signal transduction is assessed. We recently used both of these approaches to demonstrate that Src family tyrosine kinases and PI 3-K $\alpha$ are required for S-phase entry induced by PDGF (Twamley-Stein et al., 1993; Roche et al., 1994b). By using both approaches we investigated in this report the role of rasGAP, PLC $\gamma$. Syp. Nck and Shc on $S$-phase entry as well as on $c$-fos gene expression induced by PDGF.

\section{Results}

\section{Requirement of Shc, Nck, Syp and PLC $\gamma$ for PDGF-induced S-phase entry}

To address the functions of these signalling molecules during S-phase entry, we first used the dominant negative approach. Constructs that encode glutathione $S$-transferase (GST) fused to the SH2 domain of each protein were expressed in bacteria and the proteins were purified using glutathione-Sepharose. The fusion proteins used in this study are listed in Figure 1. Syp, PLC $\gamma$ and rasGAP contain two $\mathrm{SH} 2$ domains, and we generated fusion proteins containing either single $\mathrm{SH} 2$ domains, or both together, and-in the case of rasGAP-also the whole SH2/SH3 regulatory region. We next tested whether purified proteins were properly folded, as judged by their ability to associate with the activated human PDGF receptor. Immobilized GST fusion proteins were incubated with insect cell lysates expressing the human PDGF receptor and, after extensive washing. bound receptor was detected by its ability to autophosphorylate in vitro. As shown in Figure 2, all the fusion proteins were able to associate with the PDGF receptor, whereas GST alone was not.

The effects of purified SH2 domains on the mitogenic response induced by PDGF were then analysed. Quiescent NIH 3T3 cells were seeded onto coverslips and GST fusion proteins were injected into the cytoplasm at a concentration of $3-4 \mathrm{mg} / \mathrm{ml}$. Cells were then stimulated 



Fig. 3. The Syp-SH2 domain but not the GAP-SH2(N) domain inhibits PDGF-stimulated DNA synthesis in NIH 3T3 cells. Quiescent cells seeded onto coverslips were injected with GST-SH2 Syp (right) or GST-SH2(N) GAP (left) premixed with rabbit IgG (1 mg/ml) as indicated. PDGF and $\mathrm{BrdU}$ were added to the cells, and $18 \mathrm{~h}$ later the cells were fixed and stained. Injected cells were visualized with a fluorescein-conjugated anti-rabbit antibody (A and $\mathbf{C}$ ) and BrdU incorporation was visualized with Texas red-conjugated anti-mouse antibody (B and $\mathbf{D})$. The white arrowheads mark the position of the microinjected cells.

with PDGF $(25 \mathrm{ng} / \mathrm{ml})$ and bromodeoxyuridine (BrdU) was added into the medium as a marker of S-phase entry. After $18 \mathrm{~h}$ of incubation at $37^{\circ} \mathrm{C}$, cells were fixed and immunostaining performed. An example of a microinjection experiment is shown in Figure 3. Most of the cells microinjected with a fusion protein containing the two Syp SH2 domains (Syp-SH2) did not enter S phase, whereas the surrounding cells did. In contrast, cells injected with the N-terminal SH2 domain of GAP [GAP-SH2(N)] responded to PDGF as well as the surrounding cells. This suggested that Syp, but not GAP, is necessary for PDGFinduced S-phase entry. To quantitate this inhibition and extend the analysis to other $\mathrm{SH} 2$-containing proteins, statistical analysis was then performed using several hundred microinjected cells (Figure 4). As observed previously (Roche et al., 1994b, 1995), PDGF at $25 \mathrm{ng} / \mathrm{ml}$ drives $\sim 65 \%$ of the cell population into $\mathrm{S}$ phase. $\mathrm{SH} 2$ domains from Shc, Nck, Syp and PLC $\gamma$ inhibited this response by $\sim 80 \%$. In contrast, the $\mathrm{SH} 2$ domains of rasGAP had no effect. Interestingly, whereas Syp-SH2(C) and $\mathrm{PLC} \gamma-\mathrm{SH} 2(\mathrm{~N})$ were inhibiting, Syp-SH2(N) and $\mathrm{PLC} \gamma-\mathrm{SH} 2(\mathrm{C})$ were not, even at concentrations up to $8 \mathrm{mg} / \mathrm{ml}$ (S.Roche and S.A.Courtneidge, data not shown). Taken together, these data suggest that all these signalling proteins, except rasGAP, are necessary for PDGF-induced DNA synthesis.

To confirm the function of Shc, Syp, Nck and PLC $\gamma$ in S- phase entry, we used antibodies specific for each molecule. Antibodies were raised against various domains of the protein (Figure 5): anti-Shc, -Syp and -PLC $\gamma$ antibodies were raised against the $\mathrm{SH} 2$ domains, anti-Nck against the SH3 triplet present in the $\mathrm{N}$-terminal part of the molecule and the rasGAP antibody recognized the whole $\mathrm{SH} 2 / \mathrm{SH} 3$ regulatory region of the enzyme. Because most antibodies are directed against $\mathrm{SH} 2$ domains we tested their ability to recognize the cognate protein when associated with the PDGF receptor. Antibodies were affinitypurified and immunoprecipitations were performed from PDGF-stimulated cell lysates. As shown in Figure 6, antibodies specific for Shc, Nck, PLC $\gamma$ did not co-immunoprecipitate the activated receptor whereas $\sim 1 \%$ of the total receptor content was present in the rasGAP immunocomplex. As described in previous reports (Ellis et al., 1990; Pelicci et al., 1992; Feng et al., 1993) the antibodies did immunoprecipitate the signalling proteins from cell lysates (S.Roche and S.A.Courtneidge, data not shown).

We next tested the effect of these antibodies in vivo. Purified $\operatorname{IgG}(1-2 \mathrm{mg} / \mathrm{ml})$ was injected into quiescent cells seeded onto coverslips and the ability of injected cells to respond to PDGF was analysed as described above. Statistical analyses of these experiments are shown in Figure 7A. Antibodies specific for Shc, Nck, Syp and PLC $\gamma$ inhibited $65-75 \%$ of the mitogenic response induced by PDGF, whereas the rasGAP antibody had no effect. In 


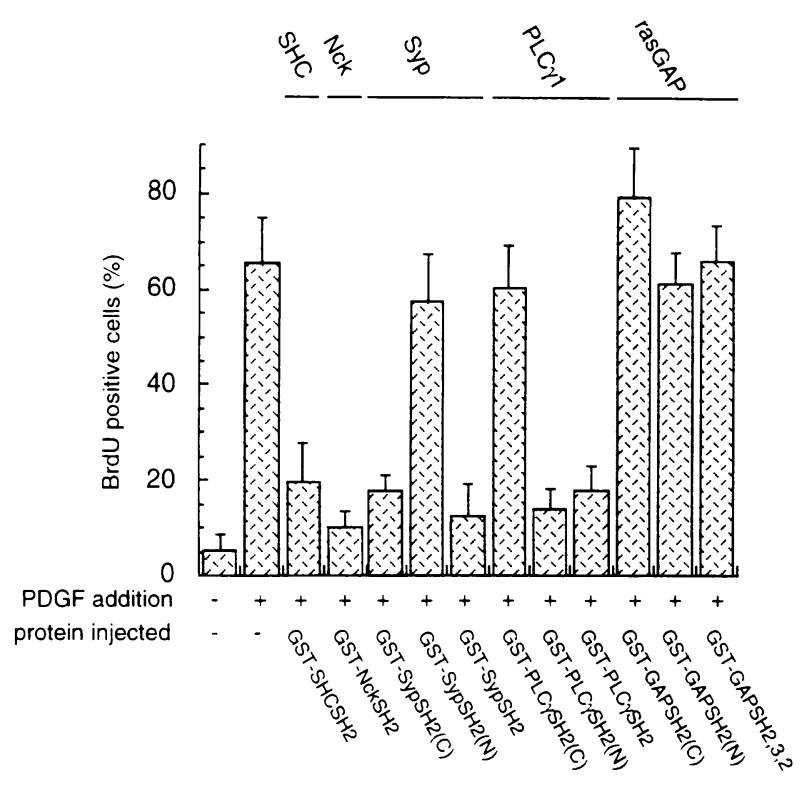

Fig. 4. Inhibition of PDGF signalling in fibroblasts by GST-SH2 fusion proteins. Quiescent NIH 3 T3 cells were given microinjections of purified GST-SH2 fusion proteins as indicated. stimulated with $25 \mathrm{ng} / \mathrm{ml}$ PDGF. and processed for immunofluorescence as described in Figure 3. For each experiment, several coverslips were analysed and the percentage of BrdU-positive cells was calculated. For the microinjected cells. DNA synthesis was calculated by the following formula: \% of cells $=($ number of BrdU-positive injected cells $) /($ total number of injected cells) $\times 100$. The results from several experiments $(n>3)$ have been averaged: the mean and standard deviation of the mean are shown.

contrast, anti-Shc, -Nck, -Syp and -GAP antibodies did not affect the response induced by $10 \%$ fetal calf serum (FCS) (Figure 7B). Therefore the inhibiting effect observed was specific to the PDGF mitogenic response, rather than being due to a toxic effect of antibody microinjection. Interestingly, when PLC $\gamma$ antibody was injected, a strong inhibition was also observed when cells were stimulated with serum. This inhibition was largely reversed when the antibody was complexed with its antigen before introduction (Figure 7B). Altogether. these results confirm what was observed with the GST fusion proteins, i.e. a requirement for Shc, Nck, Syp and PLC $\gamma$ for PDGFinduced S-phase entry. Furthermore, these data suggest that Shc, Nck and Syp are necessary for the mitogenic response induced by PDGF but not serum, and that PLC $\gamma$ is required for the response induced by both stimuli.

\section{Requirement for Shc, Syp and PLCy, but not for Nck, Src family tyrosine kinases and PI 3-K for cFos expression}

We next examined which of the signalling molecules are involved in cFos expression. We took advantage of cells engineered to express $\beta$-galactosidase under the control of the $c$-fos promoter (LIA cells). When synchronized in $\mathrm{G}_{0}$, cells did not express $\beta$-galactosidase (see Figure $8 \mathrm{~A}$ ); however, a strong nuclear enzymatic activity was detected in most cells shortly after PDGF $(25 \mathrm{ng} / \mathrm{ml})$ addition. This activity was detected after $30 \mathrm{~min}$ and was maximal after $90 \mathrm{~min}$ (Figure $8 \mathrm{C}$ ). We then tested the effect of $\mathrm{SH} 2$ fusion proteins on $c$-fos promoter activation in LIA cells. As shown in Figure 8, GAP-SH2(N) did not affect the response induced by PDGF (Figure $8 \mathrm{~B}$ and $\mathrm{C}$ ) whereas

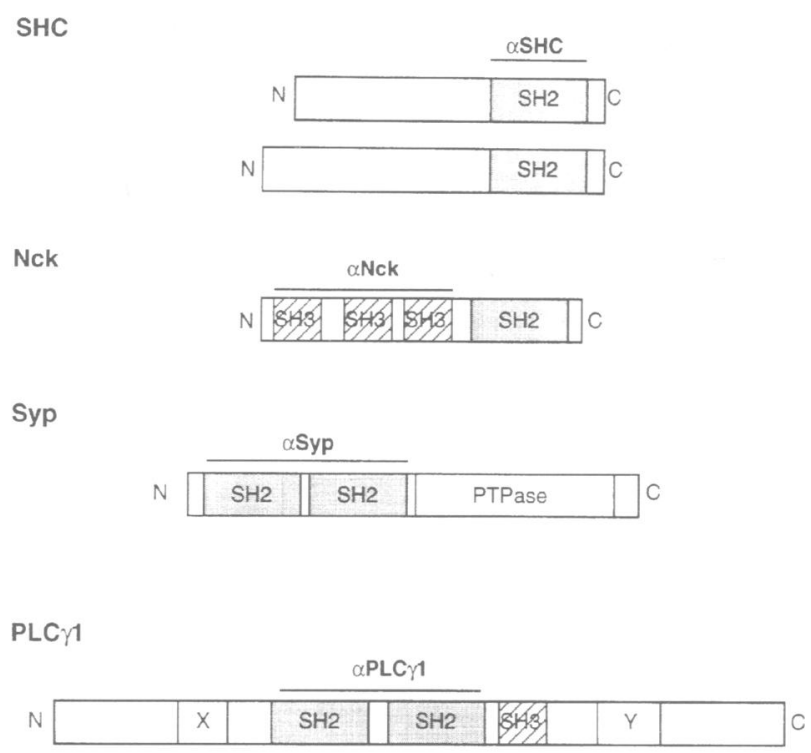

rasGAP

\begin{tabular}{|c|c|c|c|}
\hline & \multicolumn{2}{|c|}{$\alpha$ GAP } & \\
\hline N & $\mathrm{SH} 2$ & $\mathrm{SH} 2$ & GTPase \\
\hline
\end{tabular}

Fig. 5. Region of the signalling protein recognized by antibodies used in the study. Represented are the regions of the molecules used for generating the specific antibodies used in this study.

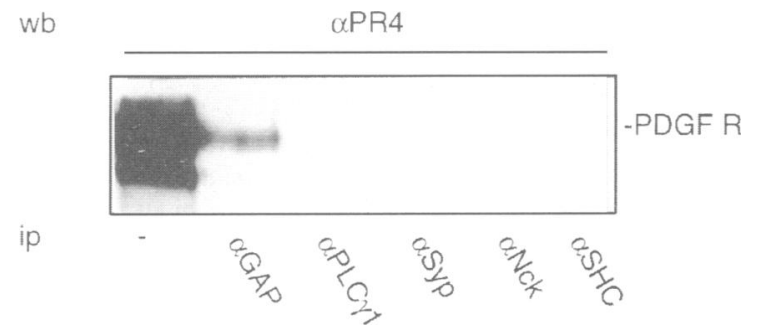

Fig. 6. Antibodies do not recognize the signalling proteins when preassociated with the PDGF receptor in fibroblasts. Signalling proteins were immunoprecipitated from PDGF-stimulated quiescent fibroblasts with affinity-purified antibodies as indicated and the presence of the PDGF receptor was revealed by Western blotting using anti-PR-4 antibody. In the first lane, $10 \%$ of the total cell lysate was used as a positive control. The band corresponding to the PDGF-receptor (PDGF $\mathrm{R})$ is indicated.

most cells containing Syp-SH2 did not show any $\beta$-galactosidase activity (Figure $8 \mathrm{D}$ and $\mathrm{E}$ ). This suggested that Syp-SH2 but not GAP-SH2(N) was necessary for cFos expression. To confirm this effect, statistical analyses were performed from several hundred cells (Figure 9A). PDGF induced expression of $\beta$-galactosidase activity in $\sim 75 \%$ of the cell population. This response was inhibited by $50-80 \%$ in the presence of Shc-SH2, Syp-SH2 and PLC $\gamma-\mathrm{SH} 2$. However, no significant effect was observed in cells containing Nck-SH2 or GAP-SH2(N). We also tested whether Src family tyrosine kinases and phosphatidylinositol 3-kinase (PI 3-K), two other SH2-containing enzymes that interact with the activated PDGF receptor, were involved in this response. GST proteins fused to Fyn-SH2 and the N-terminal SH2 domain of the regulatory subunit of PI 3-K, p85 $\alpha$, were then injected into cells. As 
A
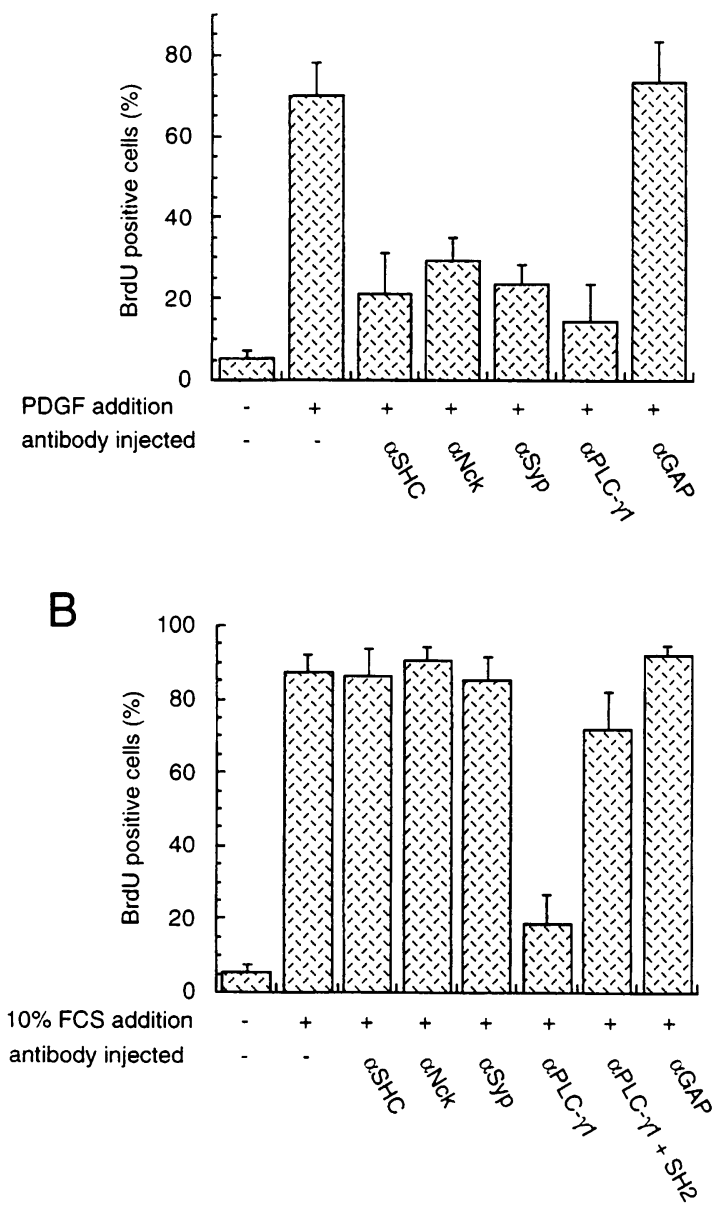

Fig. 7. Effect of antibodies on PDGF and serum-induced DNA synthesis. Quiescent NIH 3T3 cells were given microinjections of antibody pre-blocked or not with its antigen as indicated, stimulated with $25 \mathrm{ng} / \mathrm{ml}$ PDGF (A) or with 10\% FCS (B), and immunostained as described in Figure 3. For each experiment, several coverslips were analysed and the percentage of BrdU-positive cells calculated as described in Figure 4. The results from several experiments $(n>3)$ have been averaged; the mean and standard deviation of the mean are shown.

shown in Figure 9A, no effect of these fusions was observed on PDGF-evoked $\beta$-galactosidase expression.

We then tested the effect of the antibodies on $\beta$-galactosidase expression. As shown in Figure 9B, Y13 259 , a neutralizing antibody to Ras activity, inhibited the response induced by PDGF by $>90 \%$. This result confirmed what has been previously reported, i.e. that $c$-fos expression is controlled by a Ras-dependent pathway (Treisman, 1994). In addition, anti-Syp and anti-PLC $\gamma$ inhibited this response by $80 \%$ and anti-Shc by $65 \%$. However, antibodies specific for GAP and Nck did not affect the expression of the reporter gene. Moreover, two neutralizing antibodies to Src family tyrosine kinases ( $\alpha$ cst.1) (Roche et al., 1995) and to PI 3-K $\alpha(\alpha p 110 \alpha .1)$ (Roche et al., 1994a) respectively that have been shown to inhibit the mitogenic response induced by PDGF (Twamley-Stein et al., 1993; Roche et al., 1994b), did not affect this response. Collectively, these results suggest that Shc, Syp and PLC $\gamma$ are necessary for PDGF-evoked cFos expression, whereas Nck, PI 3-K $\alpha$ and Src family tyrosine kinases are not.

\section{Discussion}

We have used two different approaches to identify which signalling molecules are necessary for the PDGF mitogenic response. In the first method, we used a dominant negative approach in which the isolated $\mathrm{SH} 2$ domain of a signalling protein was investigated for its ability to inhibit PDGFinduced S-phase entry. In vivo, the injected proteins may prevent binding of the endogeneous signalling molecule with the PDGF receptor or with their effectors, thereby blocking the propagation of a mitogenic signal. Since an $\mathrm{SH} 2$ domain can in principle bind with some affinity to any phosphotyrosine-containing protein, one could argue that the resulting inhibitions might be non-specific. However, it is unlikely that this occurred in our conditions since several injected $\mathrm{SH} 2$ domain fusion proteins did not have any effect in vivo (GAP-SH2 domains for example). In particular, in some cases the individual SH2 domains of the same molecule had different effects on S-phase entry; thus, the C-terminal domain of PLC $\gamma$ did not show any activity whereas the $\mathrm{SH} 2(\mathrm{~N})$ inhibited S-phase entry to $>80 \%$, suggesting that $\mathrm{SH} 2$ domains of a same protein may have a different contribution for signalling.

The second approach involved microinjection of antibodies specific for the same signalling proteins from which the $\mathrm{SH} 2$ domains were derived. Since these antibodies are directed against the $\mathrm{SH} 2$ or $\mathrm{SH} 3$ domains of the proteins, they may block the association of the endogenous proteins with the activated receptor or with its effectors. This hypothesis is strengthened by the fact that the antibodies are poor in recognizing the signalling proteins when complexed with the receptor in vitro. The block to PDGF stimulation observed following antibody microinjection was specific since, with the exception of PLC $\gamma$, injected cells could respond to serum. In the case of PLC $\gamma$, specificity of inhibition was shown by the fact that the effect was largely reduced when antibody was pre-blocked by its antigen. Collectively, both approaches demonstrate a requirement for Shc, Nck, Syp and PLC $\gamma$, but not rasGAP, in PDGF-induced mitogenesis. GAP overexpression has been shown to reverse cell transformation induced by both vSrc and cRas (Zhang et al., 1990; Nori et al., 1991), suggesting that it is a negative regulator of Ras activity and S-phase entry. The fact that GAP function was apparently not required for PDGF-induced DNA synthesis is in agreement with such an hypothesis. Nevertheless, we cannot rule out that, in the context of PDGF stimulation, GAP activation can be involved in other responses such as cytoskeletal rearrangement. It has been reported that the N-terminal part of the molecule could regulate cell shape and attachment induced by several growth factors (McGlade et al., 1993).

Are these signals necessary for DNA synthesis induced by all mitogens? We have previously shown that tyrosine kinase receptors use signals such as Src family protein tyrosine kinases and PI 3-K $\alpha$ that are not necessary for mitogens that interact with seven transmembrane receptors (Twamley-Stein et al., 1993; Roche et al., 1994b, 1995). We concluded that tyrosine kinase receptors use unique signals for cell growth. It has been previously suggested that the EGF and insulin receptors (Sasaoka et al., 1994; Xiao et al., 1994) require Shc and Syp to mediate a mitogenic response. Therefore, the role of Shc and Syp 

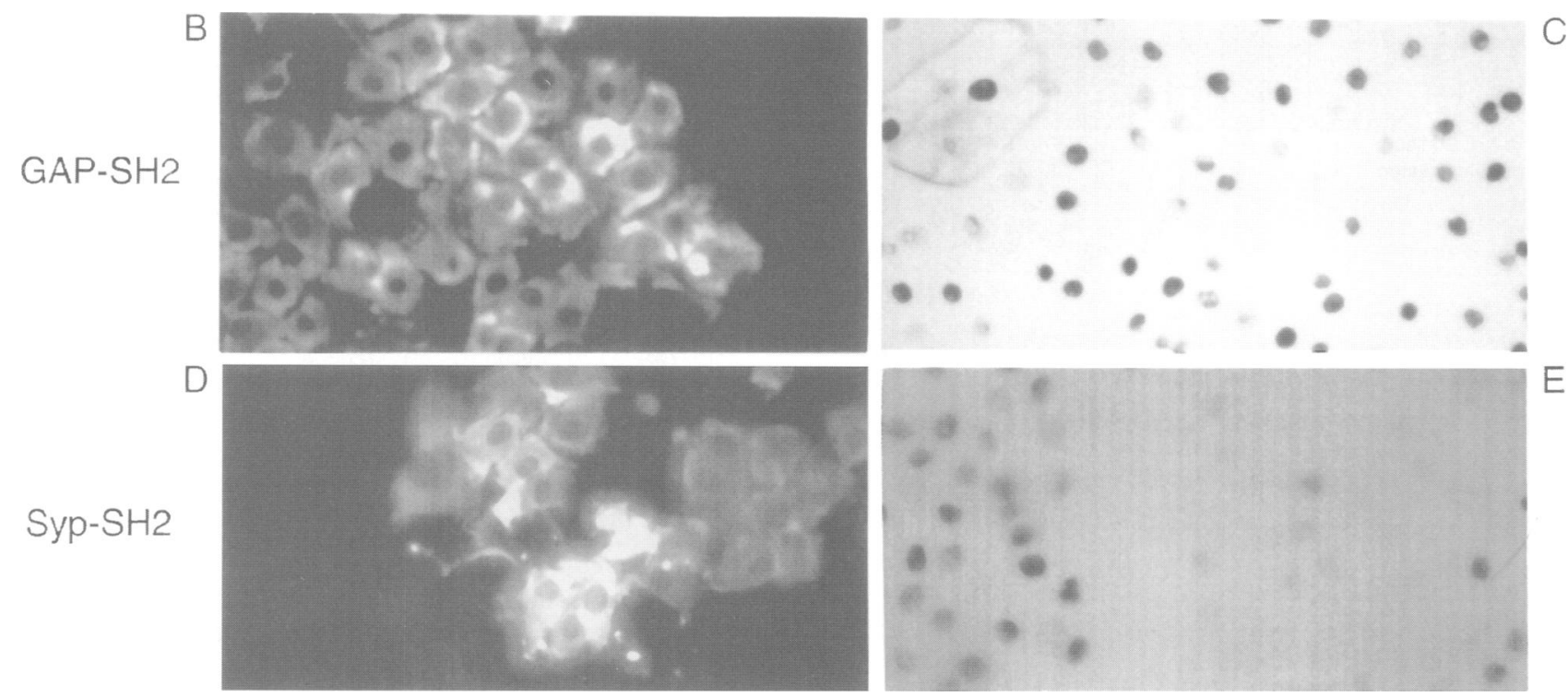

Fig. 8. Syp-SH2 but not GAP-SH2(N) blocked $c$-fos-driven $\beta$-galactosidase expression in PDGF-stimulated LIA cells. Quiescent LIA cells seeded onto coverslips were injected with GST-SH2 Syp (D and E) or GST-SH2(N) GAP (B and C) premixed with fluorescein-conjugated dextran (2\%) as indicated. Cells were incubated in the presence (B-E) or absence (A) of PDGF $(25 \mathrm{ng} / \mathrm{ml})$ for $90 \mathrm{~min}$, fixed and stained for $\beta$-galactosidase activity as described in Materials and methods. Injected cells were visualized by fluorescent microscopy [(B) and (D)] and $\beta$-galactosidase expression using inversion microscopy $[(\mathrm{A}) .(\mathrm{C})$ and $(\mathrm{E})]$.

in DNA synthesis may be common for tyrosine kinase receptor signalling. However, we did not observe any inhibition with antibodies specific to Nck, Shc or Syp on the serum response. Taken together, these data suggest that tyrosine kinase receptors transmit mitogenic signals through specific signalling proteins such as Src family tyrosine kinases, PI 3-K $\alpha$, Syp, Shc and Nck. Our results also suggest that both mitogens use common signals like PLC $\gamma$ for cell growth: antibody specific to this phospholipase inhibited S-phase entry induced by both PDGF and serum in NIH 3 T3 cells. A requirement of PLC $\gamma$ activity for S-phase entry has been already shown (Smith et al., 1990) and our results are in total agreement with these previous reports. In addition our data suggest that the SH2 domains of PLC $\gamma$ are important for both PDGF and serum signalling.

Subsequently, we analysed how these intracellular proteins signal. We used both microinjection approaches described above to determine which proteins are important for $\mathrm{cFos}$ expression, an early event of $\mathrm{G}_{1}$ phase important for DNA synthesis. For this purpose we used cells expressing $c$-fos-driven $\beta$-galactosidase. Inhibition of enzyme expression was detected when inhibiting signal transmission initiated by Shc. Syp and PLC $\gamma$. These effects were specific since other molecules were not required for c-fos promoter activation, i.e. Src family tyrosine kinases, PI 3-K and Nck. These results suggest that several pathways may converge on cFos expression. In the context of the PDGF response this event is regulated by Ras activity (Treisman, 1994) and a link between Shc, Syp and PLC $\gamma$ and PDGF-induced Ras-activation has been previously established (Valius and Kazlauskas, 1993; van der Geer and Hunter, 1994; Rivard et al., 1995). These results suggest that all these signalling proteins are necessary for Ras activation above a threshold that will permit signal propagation. There are several lines of evidence in favour of this hypothesis. For example, both Shc and Syp were shown to be required for the $c$-fos response induced by thrombin, a mitogen that interacts with a seventransmembrane receptor (Chen et al., 1995; Rivard et al.. 1995), confirming that several signalling molecules may be involved in mitogen-induced Ras activation. Also, several groups have shown that the strength of the signal generated by EGF or insulin could influence the downstream response, leading to cell differentiation of PC12 cells instead of cell growth (Dikic et al., 1994; Traverse et al., 1994). Finally, a PDGF receptor mutant that does not bind PLC $\gamma$ was impaired in cell growth induction at submaximal ligand concentration and the response was largely restored at maximal concentration (Valius et al.. 1993), suggesting that other signals could overcome PLC $\gamma$ signalling when maximally stimulated. Therefore one can propose that PDGF generates interconnecting signals that are all necessary for maximal response. It is of some note that Shc antibody had a greater inhibition on DNA synthesis than on cFos activation. This would suggest that 
A
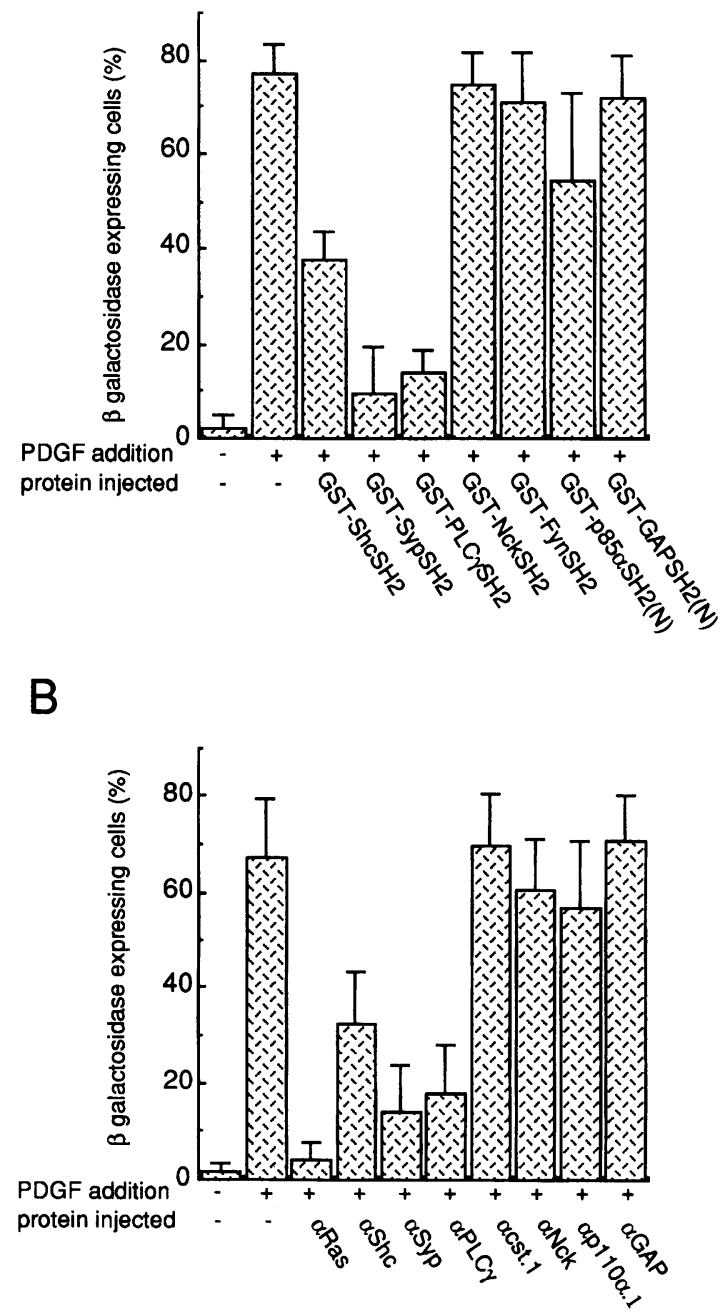

Fig. 9. Inhibition of PDGF-stimulated $c$-fos expression. Quiescent LIA cells were given microinjections of purified GST-SH2 fusion proteins (A) or purified antibody (B) as indicated, stimulated with $25 \mathrm{ng} / \mathrm{ml}$ PDGF, and immunostained as described in Figure 8. For each experiment, several coverslips were analysed and the percentage of $\beta$-galactosidase-positive cells was calculated. For the microinjected cells, $c$-fos expression was calculated by the following formula: $\%$ of cells $=$ (number of injected cells showing $\beta$-galactosidase activity $) /$ (total number of injected cells) $\times 100$. Results from several experiments $(n>3)$ have been averaged; mean and standard deviation of the mean are shown.

Shc also plays crucial roles outside the Ras pathway that are important for mitogenesis.

Other signalling molecules such as Src family tyrosine kinases, PI 3-K and Nck-all important for PDGF-induced S-phase entry-did not affect cFos expression, suggesting that PDGF also uses Ras-independent pathways. We have previously observed that a constitutive expression of cMyc, but not cFos, rescued the PDGF signalling block caused by kinase-inactive Src whereas cFos but not cMyc overcame the block induced by a dominant negative form of Ras (Barone and Courtneidge, 1995). From these results we surmise the existence of a Src pathway that culminates in cMyc expression in a Ras-independent manner. A neutralizing antibody that recognizes an epitope common to Src, Fyn and Yes did not affect the PDGF-mediated cFos response, consistent with the DNA injection experi- ments. PI 3-K inhibition may be another example of a Ras-independent signal necessary for the PDGF response. A relationship between PI 3-K and the protein serine/ threonine involved in protein synthesis, p70 S6 kinase (Kozma and Thomas, 1994), has been proposed by several groups (Cheatham et al., 1994; Chung et al., 1994). S6 kinase plays a key role for S-phase entry (Kozma and Thomas, 1994) and recent reports suggest that PI 3-Kinduced increased kinase activity is mediated by another serine/threonine kinase c-Akt (also called PK-B) (Burgering and Coffer, 1995; Franke et al., 1995). Interestingly, c-Akt-mediated-kinase activation was poorly affected by Ras inhibition (Burgering and Coffer, 1995). Consistent with these observations we did not observe any effect of wortmannin, an inhibitor of PI 3-K activity (Ui et al., 1995), on PDGF-induced Ras-GTP loading as well as MAP kinase activation in NIH cells (S.Roche and S.A.Courtneidge, data not shown). Altogether, these observations suggest the existence of a Ras-independent pathway generated by PI 3-K activity. Finally, in the context of PDGF response, Nck may also generate a signal that is not related to cFos expression. How does Nck signal? Antibody inhibition suggests that the $\mathrm{SH} 3$ domains of Nck are important for signalling. The Ras-GTP exchange factor SOS has been shown to interact with Nck when transiently overexpressed, suggesting that in certain circumstances it can activate the Ras pathway (Hu et al., 1995). However, the lack of effect of Nck-SH2 and Nck antibody on cFos expression strongly suggests that it does not occur in the context of PDGF signalling. Similarly, overexpression of a dominant negative form of Nck did not affect the EGF-activated Ras pathway (Tanaka et al., 1995). Other proteins that interact with Nck through its SH3 domains have been recently identified, including $\mathrm{cCbl}$, the cellular homologue of the oncoprotein $\mathrm{vCbl}$ (Rivero-Lezcano et al., 1994) and the Wiskott-Aldrich syndrome protein p66 ${ }^{\text {WASP }}$ (Rivero-Lezcano et al., 1995), which could be important mediators of the Nck mitogenic pathway. However, their role in the mitogenic signal is currently unknown.

In summary, our data showed a requirement for Syp, Shc, PLC $\gamma$ and Nck for DNA synthesis induced by PDGF in fibroblasts. In addition, they strongly suggest the existence of several pathways initiated by Shc, Syp and PLC $\gamma$ that converge on Ras activation, leading eventually to cFos expression, and the existence of Ras-independent pathways initiated by Nck, Src family tyrosine kinases and PI 3-K $\alpha$. All these pathways are necessary for PDGFinduced cell growth.

\section{Materials and methods}

\section{Purification of GST fusion proteins}

pGEX that encodes for GST fusion proteins and purification of the expressed proteins have been described (Pelicci et al., 1992; Twamley et al., 1992; Feng et al., 1993; Songyang et al., 1993; Erpel et al., 1995). The expression of GST proteins in Escherichia coli was induced with isopropyl $\beta$-D-thiogalactopyranoside (IPTG) for $3 \mathrm{~h}$; cells were then centrifuged and lysed in phosphate buffer solution (PBS) by sonication. After adding Triton X-100 the lysate was clarified by centrifugation at $12000 \mathrm{~g}$. GST fusion proteins were bound to $4 \mathrm{~B}$ glutathione-Sepharose beads (Pharmacia), washed three times in PBS/ $1 \%$ Triton X-100 to remove non-specific bound proteins, and eluted with an excess of glutathione. Fractions were then dialysed in order to remove glutathione and concentrated up to $3-4 \mathrm{mg} / \mathrm{ml}$ using a minicon 
microconcentrator (Amicon). Before microinjection, proteins were premixed with purified non-immune rabbit $\operatorname{IgG}$ at a final concentration of $1 \mathrm{mg} / \mathrm{ml}$.

\section{Antibody purification}

Generation of antibodies was as described previously (Ellis et al., 1990; Pelicci et al., 1992; Feng et al., 1993; Roche et al., 1994a, 1995) except for PLC $\gamma$ antibody which was raised against the GST-SH2 domains of the protein. Sera were affinity-purified as described by Roche et al. (1994b). Briefly, ammonium sulphate-precipitated sera were first loaded onto Sepharose column bound to GST in order to remove antibodies raised against the GST part of the antigen. Non-bound $\operatorname{IgG}$ was loaded onto Sepharose columns to which GST fusion protein had been coupled, then washed with $10 \mathrm{mM}$ sodium phosphate-500 $\mathrm{mM} \mathrm{NaCl}$ buffer. $\mathrm{pH}$ 7. Antibody was eluted with $1 \mathrm{mM}$ propionic acid, and fractions were collected into $1 \mathrm{M}$ ice-cold sodium phosphate buffer. $\mathrm{pH} 7$, and concentrated to $1-2 \mathrm{mg} / \mathrm{ml}$. Non-immune rabbit IgG and Y13 259 monoclonal antibodies were purified from normal rabbit and hybridoma cell supernatants respectively by using a protein $\mathrm{G}$ column (Pharmacia). Y13 259 was concentrated to $3-4 \mathrm{mg} / \mathrm{ml}$ and premixed with rabbit $\mathrm{IgG}$ to a final concentration of $1 \mathrm{mg} / \mathrm{ml}$ before injection.

\section{Biochemistry}

Cell lysates were made as described previously (Roche et al.. 1994a). Briefly, cells were washed twice with ice-cold TBS $(20 \mathrm{mM}$ Tris, $\mathrm{pH} 7.5$. $150 \mathrm{mM} \mathrm{NaCl}, 0.1 \mathrm{mM}$ sodium orthovanadate) and then lysed with $0.5 \mathrm{ml}$ LB $(20 \mathrm{mM}$ Tris, pH $8,150 \mathrm{mM} \mathrm{NaCl}, 1 \%$ Nonidet P40, $1 \%$ aprotinin, $20 \mathrm{mM}$ leupeptin, $10 \mathrm{mM} \mathrm{NaF}, 0.1 \mathrm{mM}$ sodium orthovanadate) and centrifuged for $10 \mathrm{~min}$ at $12000 \mathrm{~g}$. Supernatants were used for biochemical analysis. For binding assays, GST fusion proteins were bound to glutathione-Sepharose beads, and after extensive washing incubated with Sf9 cell lysate expressing the human PDGF receptor. The complexes were then washed three times in LB and once in TBS. Kinase assays were performed for $5 \mathrm{~min}$ at $30^{\circ} \mathrm{C}$ in a buffer containing $5 \mathrm{mM} \mathrm{MnCl}, 1 \mathrm{mM}$ dithiothreitol, $20 \mathrm{mM}$ HEPES, $\mathrm{pH} 8$, and $1 \mu \mathrm{Ci}\left[\gamma_{-}{ }^{32} \mathrm{P}\right]$ ATP. Labelled proteins were then separated on a $7.5 \%$ polyacrylamide gel and the dried gel was exposed for autoradiography.

For antibody characterization, proteins were immunoprecipitated using affinity-purified $\operatorname{IgG}$ from quiescent fibroblast cell lysates stimulated for $5 \mathrm{~min}$ with $50 \mathrm{ng} / \mathrm{ml}$ PDGF (Upstate Biotechnology) as described in Roche et al. (1994a). After extensive washes, the bound proteins were separated on a $7.5 \%$ polyacrylamide gel, and transferred onto a nitrocellulose membrane using the miniblot-SDE system (Millipore). The filters were incubated with PDGF receptor polyclonal antibody, PR-4 (dilution 1:500) (Roche et al., 1994a). Detection was performed by incubation with protein A coupled to horseradish peroxidase followed by ECL chemiluminescence (Amersham).

\section{Cell culture technique}

Sf9 cells were grown in Grace's medium containing 10\% FCS. Cells were then infected with recombinant baculovirus encoding for the human PDGF receptor (a generous gift from D.Morrison) for $48 \mathrm{~h}$ before lysis as described previously (Roche et al., 1994a). LIA fibroblasts have been described by Schilling et al. (1991). NIH 3T3 and LIA cells were grown at $37^{\circ} \mathrm{C}$ in Dulbecco's modified Eagle's medium (DMEM) containing $10 \%$ FCS. Cells were made quiescent by replacing the medium with DMEM containing $0.5 \%$ FCS, transferrin $(5 \mu \mathrm{g} / \mathrm{ml})$ and insulin $(5 \mu \mathrm{g} / \mathrm{ml})$ for $24-30 \mathrm{~h}$ before stimulation.

\section{Microinjection of cells}

Cells were grown on coverslips to $70 \%$ confluence, then made quiescent as described above. Before microinjection. HEPES was added to a concentration of $20 \mathrm{mM}$. Purified proteins were injected into the cytoplasm with an automatic microinjection system (AIS. Zeiss) as described previously (Roche et al., 1994b) just before growth factor addition. In the case of $c$-fos-driven $\beta$-galactosidase assays, proteins were premixed with fluorescein-conjugated dextran (Dianova) at a final concentration of $1 \%$. Typically, $100-150$ cells were injected per coverslip. The needles used for microinjection were pulled with a Fleming-Brown micropipette puller. DNA synthesis was monitored by adding BrdU (Sigma). The cells were further incubated for $18 \mathrm{~h}$ (for BrdU incorporation) and for $90 \mathrm{~min}$ (for c-fos expression) and then fixed for immunostaining.

\section{Staining}

Coverslips were washed once with PBS and fixed for 5 min with cold methanol in the case of NIH 3T3 cells and for 15 min with $2 \%$ paraformaldehyde at room temperature in the case of LIA cells. NIHinjected cells were detected by incubating coverslips with fluoresceinconjugated goat anti-rabbit antibody (Dianova) diluted in PBS (1:100) for $30 \mathrm{~min}$ and then washed three times with PBS. To analyse DNA synthesis, cells were incubated for $10 \mathrm{~min}$ with $1.5 \mathrm{M} \mathrm{HCl}$, washed three times with PBS. stained with monoclonal anti-BrdU antibody (Boehringer) and stained with Texas red-conjugated anti-mouse antibody (Dianova). For $\beta$-galactosidase expression, cells were incubated for $16 \mathrm{~h}$ in the dark with a solution containing $1 \mathrm{mg} / \mathrm{ml} \mathrm{4-chloro-5-bromo-3-}$ indolyl-beta-galactosidase (X-gal) (Sigma), $10 \mathrm{mM}$ potassium ferricyanide, $10 \mathrm{mM}$ potassium ferrocyanide, $10 \mathrm{mM} \mathrm{MgCl} 2,0.1 \%$ Nonidet P40 and sodium desoxycholate (Schilling et al., 1991). Cells were then washed three times with PBS. All coverslips were finally washed in PBS containing Hoechst 33258 (Sigma), rinsed in water, and mounted in Moviol (Hoechst) on glass slides. Slides were viewed with an axiophot fluorescence microscope.

\section{Acknowledgements}

We thank T.Curran for providing LIA cells and Sara Jacob for technical assistance. We thank our colleagues for discussion and critical reading of the manuscript. This work was supported by a grant from the Human Frontiers Science Programme to T.P and S.A.C. S.R. is supported by the 'Institut National de la Santé et de la Recherche Médicale'. T.P. is a Terry Fox Cancer Research Scientist of the National Cancer Institute of Canada.

\section{References}

Barone.M.V. and Courtneidge.S.A. (1995) Myc but not Fos rescue of PDGF signaling block caused by kinase inactive Src. Nature, 378. $509-512$.

Biro.S.. Fu.Y.-M., Yu.Z.-X. and Epstein.S.E. (1993) Inhibitory effects of antisense oligodeoxynucleotides targeting c-myc mRNA on smooth muscle cell proliferation and migration. Proc. Natl Acad. Sci. USA. 90, 654-658.

Burgering.B.M.T. and Coffer.P.J. (1995) Protein kinase B (c-Akt) in phosphatidylinositol-3-OH kinase signal transduction. Nature, 376, 599-602.

Cheatham,B., Vlahos,C.J., Cheatham,L., Wang.L., Blenis,J. and Kahn.C.R. (1994) Phosphatidylinositol 3-kinase activation is required for insulin stimulation of pp70 S6 kinase, DNA synthesis, and glucose transporter translocation. Mol. Cell. Biol.. 14, 4902-4911.

Chen,Y.-H., Grall,D., Salcini,A.E., Pelicci,P.G., Pouyssegur,J. and Van Obberghen-Schilling.E. (1995) Shc adaptor proteins are key transducers of mitogenic signaling mediated by the $G$ protein-coupled thrombin receptor. EMBO J., 15, 1037-1044.

Chung.J.. Grammer.T.C.. Lemon.K.P.. Kazlauskas,A. and Blenis.J. (1994) PDGF- and insulin-dependent $\mathrm{pp} 70^{\mathrm{S} 6 \mathrm{k}}$ activation mediated by phosphatidylinositol-3-OH kinase. Nature, 370, 71-75.

Dikic,I., Schlessinger.J. and Lax.I. (1994) PC12 cells overexpressing the insulin receptor undergo insulin-dependent neuronal differentiation. Curr. Biol., 4, 702-708.

Ellis,C.. Moran,M., McCormick,F. and Pawson,T. (1990) Phosphorylation of GAP and GAP-associated proteins by transforming and mitogenic tyrosine kinases. Nature, 343, 377-379.

Erpel,T., Superti-Furga.G. and Courtneidge,S.A. (1995) Mutational analysis of the Src SH3 domain: the same residues of the ligand binding surface are important for intra- and intermolecular interactions. EMBO J., 14, 963-975.

Feng.G.-S., Hui.C.-C. and Pawson.T. (1993) SH2-containing phosphotyrosine phosphatase as a target of protein-tyrosine kinases. Science. 259. 1607-1611.

Franke.T.F., Yang.S.-I., Chan,T.O., Datta.K., Kazlauskas,A., Morrisson.D.K. Kaplan.D.R. and Tsichlis.P.N. (1995) The protein kinase encoded by the Akt proto-oncogene is a target of the PDGFactivated phosphatidylinositol 3-kinase. Cell, 81, 727-736.

Holt,J.T., Gopal,V., Moulton,A.D. and Nienhuis,A.W. (1986) Inducible production of c-fos antisense RNA inhibits $3 \mathrm{~T} 3$ cell proliferation. Proc. Natl Acad. Sci. USA, 83, 4794-4798.

Hordijk.P.L., Verlaan.I., van Corven,E.J. and Moolenaar.W.H. (1994) Protein tyrosine phosphorylation induced by lysophosphatidic acid in rat-1 fibroblasts. J. Biol. Chem., 269, 645-651.

Hu,Q., Milfay,D. and Williams.L.T. (1995) Binding of Nck to SOS and activation of ras-dependent gene expression. Mol. Cell. Biol., 15. $1169-1174$ 


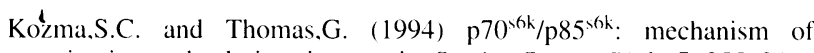
activation and role in mitogenesis. Semin. Cancer Biol., 5, 255-260.

Kumagai,N.. Morii.N.. Fujisawa,K.. Yoshimasa,T.. Nakao,K. and Narumiya.S. (1993) Lysophosphatidic acid induces tyrosine phosphorylation and activation of MAP-kinase and focal adhesion kinase in cultured Swiss 3 T3 fibroblasts. FEBS Lett., 329, 273-276.

Lev,S., Moreno,H.. Martinez,R., Canoll.P.. Peles,E., Musacchio,J.M., Plowman,G.D.. Rudy,B. and Schlessinger.J. (1995) Protein tyrosine kinase PYK2 involved in $\mathrm{Ca}^{2+}$-induced regulation of ion channel and MAP kinase functions. Nature, 376. 737-745.

McGlade.J.. Brunckhorst.B.. Anderson.D., Mbamalu.G.. Settleman.J., Dedhar,S., Rozakis-Adcock,M., Chen.L.B. and Pawson.T. (1993) The $\mathrm{N}$-terminal region of GAP regulates cytoskeletal structure and cell adhesion. EMBO J., 12, 3073-3081

Mori.S., Rönnstrand.L.. Yokote.K., Engström.A., Courtneidge.S.A., Claesson-Welsh.L. and Heldin.C.-H. (1993) Identification of two juxtamembrane autophosphorylation sites in the PDGF $\beta$-receptor. Involvement in the interaction with Src family tyrosine kinases. EMBO J.. 12. 2257-2264.

Nishikura.K. and Murray.J. (1987) Antisense RNA of proto-oncogene c-fos blocks renewed growth of quiescent 3 T 3 cells. Mol. Cell. Biol. 7. 639-649.

Nishimura,R.. Kashishian,W.L., Mondino,A., Zhou.M., Cooper,J. and Schlessinger,J. (1993) Two signaling molecules share a phosphotyrosine-containing binding site in the Platelet-Derived Growth Factor. Mol. Cell. Biol., 13, 6889-6896.

Nori.M., Vogel.U.S.. Gibbs,J.B. and Weber.M.J. (1991) Inhibition of vsrc induced transformation by a GTPase-activating protein. Mol. Cell. Biol. 11. 2812-2818.

Pawson.T. (1995) Protein modules and signaling network. Nature. 373. 573-580.

Pelicci.G. et al. (1992) A novel transforming protein (SHC) with an $\mathrm{SH} 2$ domain is implicated in mitogenic signal transduction. Cell. $\mathbf{7 0}$. 93-104.

Rivard,N.. McKenzie.F.R., Brondello.J.-M. and Pouyssegur,J. (1995) The tyrosine phosphatase PTPID but not PTPIC, is an essential mediator of fibroblast proliferation induced by tyrosine kinase and G-protein coupled receptors. J. Biol. Chem., 270, 11017-11024.

Rivero-Lezcano,O.M., Sameshima,J.H., Marcilla,A. and Robbins,K.C. (1994) Physical association between Src homology 3 elements and the protein product of the c-cbl proto-oncogene. J. Biol. Chem., 269 , $17363-17366$

Rivero-Lezcano.O.M., Marcilla,A.. Sameshima.J.H. and Robbins.K.C. (1995) Wiskott-Aldrich syndrome protein physically associates with Nck through Src homology 3 domains. Mol. Cell. Biol.. 15. 5725-5731.

Roche.S.. Dhan,R., Waterfield,M.D. and Courtneidge.S.A. (1994a) The catalytic subunit of phosphatidylinositol 3-kinase is a substrate for the platelet-derived growth factor receptor, but not for middle-T antigenpp60c-src complexes. Biochem. J., 301. 703-711.

Roche.S., Koegl.M. and Courtneidge.S.A. (1994b) The phosphatidylinositol 3-kinase $\alpha$ is required for DNA synthesis induced by some. but not all, growth factors. Proc. Natl Acad. Sci. USA, 91, 9185-9189.

Roche,S., Koegl.M., Barone,V.M., Roussel,M. and Courtneidge.S.A. (1995) DNA synthesis induced by some, but not all, growth factors requires Src family protein tyrosine kinases. Mol. Cell. Biol., 15, $1102-1109$.

Rönnstrand.L., Mori,S., Arridsson,A.-K.. Eriksson.A.. Wernstedt.C., Hellman.U., Claesson-Welsh.L. and Heldin,C.-H. (1992) Identification of two C-terminal autophosphorylation sites in the PDGF $\beta$-receptor: involvement in the interaction with phospholipase $C \gamma . E M B O J ., 11$. 3911-3926.

Sasaoka.T., Rose.D.W., Jhun,B.H., Saltiel,A.R.. Draznin.B. and Olefsky.J.M. (1994) Evidence for a functional role of Shc proteins in mitogenic signaling induced by insulin. insulin-like growth factor-1. and epidermal growth factor. J. Biol. Chem.. 269. 13689-13694.

Schilling.K., Luk,D., Morgan,J.I. and Curran.T. (1991) Regulation of a fos-LacZ fusion gene: a paradigm for quantitative analysis of stimulustranscription coupling. Proc. Natl Acad. Sci. USA, 88, 5665-5669.

Smith.M.R., Liu,Y.-L.. Kim,H., Rhee,S.G. and Kung,H.-F. (1990) Inhibition of serum- and ras-stimulated DNA synthesis by antibodies to phospholipase C. Science, 247, 1074-1077.

Songyang et al. (1993) SH2 domains recognize specific phosphopeptide sequences. Cell. 72, 767-778.

Studzinski.G.P., Brelvi,Z.S., Feldman,S.C. and Watt.R.A. (1986) Participation of c-myc protein DNA synthesis of human cells. Science. 234. 467-469.

Tanaka.M.. Gupta.R. and Mayer.B.J. (1995) Differential inhibition of signaling pathways by dominant-negative $\mathrm{SH} 2 / \mathrm{SH} 3$ adapter proteins. Mol. Cell. Biol.. 15. 6829-6837.

Traverse.S., Seedorf,K., Paterson,H., Marshall.C.J., Cohen,P. and Ullrich.A. (1994) EGF triggers neuronal differentiation of PC12 cells that overexpress the EGF receptor. Curr: Biol., 4, 694-702.

Treisman.R. (1994) Ternary complex factors: growth factor regulated transcriptional activators. Curr: Opin. Genet. Dev, 4, 96-101.

Twamley.G., Hall,B., Kypta,R. and Courtneidge,S.A. (1992) Association of Fyn with the PDGF receptor: requirement for binding and phosphorylation. Oncogene, 7, 1893-1901.

Twamley-Stein,G.M., Pepperkok,R., Ansorge,W. and Courtneidge,S.A. (1993) The Src family tyrosine kinases are required for plateletderived growth factor-mediated signal transduction in NIH-3T3 cells. Proc. Natl Acad. Sci. USA, 90, 7696-7700.

Ui,M.. Okada.T.. Hazeki,K. and Hazeki,O. (1995) Wortmannin as a unique probe for an intracellular signalling protein, phosphoinositide 3-kinase. Trends Biochem. Sci., 20. 303-307.

Valius,M. and Kazlauskas,A. (1993) Phospholipase C- $\gamma \mathrm{l}$ and phosphatidylinositol 3 kinase are the downstream mediators of the PDGF receptor's mitogenic signal. Cell, 73, 321-334.

Valius,M.. Bazenet.C. and Kazlauskas,A. (1993) Tyrosines 1021 and 1009 are phosphorylation sites in the carboxy terminus of the plateletderived growth factor receptor $\beta$ subunit and are required for binding of phospholipase $\mathrm{C} \gamma$ and a 64-kilodalton protein, respectively. Mol. Cell. Biol., 13, 133-143.

van der Geer,P. and Hunter,T. (1994) Receptor protein-tyrosine kinases and their signal transduction pathways. Annu. Rev. Cell Biol., 10. 251-337.

Wickstrom.E.L., Bacon.T.A., Gonzalez,A., Freeman,D.L., Lyman,G.H. and Wickstrom.E. (1988) Human promyelocytic leukemia HL-60 cell proliferation and $\mathrm{c}$-myc protein expression are inhibited by an antisense pentadecadeoxynucleotide targeted against c-myc mRNA. Proc. Natl Acad. Sci. USA, 85, 1028-1032.

Xiao.S.. Rose.D.W., Sasaoka,T., Maegawa,H., Burke,T.R.J., Roller,P.P., Shoelson,S.E. and Olefsky,J.M. (1994) Syp (SH-PTP2) is a positive mediator of growth factor-stimulated mitogenic signal transduction. J. Biol. Chem., 269, 21244-21248.

Yokote,K., Mori,S., Hansen,K., McGlade,J., Pawson,T., Heldin,C.H. and Claesson-Welsh.L. (1994) Direct interaction between Shc and the platelet-derived growth factor beta-receptor. J. Biol. Chem., 269 , 15337-15343.

Zachary.I., Sinnett-Smith.J. and Rozengurt.E. (1992) Bombesin, vasopressin and endothelin stimulation of tyrosine phosphorylation in Swiss 3 T 3 cells. Identification of a novel tyrosine kinase as a major substrate. J. Biol. Chem., 267, 19031-19034.

Zhang.K., Declue.J.E.. Vass,W.C., Papageorge,A.G., McCormick,F. and Lowy.D.R. (1990) Suppression of c-ras transformation by GTPaseactivating protein. Nature, 346, 671-674.

Received on March 27, 1996; revised on May 31, 1996 